\title{
An Innovative Redesign of Statics: Approach and Lessons Learned
}

\section{Dr. Yufeng Hu P.E., Western Michigan University}

Yufeng $\mathrm{Hu}$ is an assistant professor in the Civil and Construction Engineering Department at Western Michigan University. Dr. Hu received his Ph.D. degree in Structural Engineering from University at Buffalo, the State University of New York. Dr. Hu is a registered Professional Engineer in the State of California. He teaches engineering fundamental mechanics, including statics, mechanics of materials, and fluid mechanics.

Javier Martin Montefort, Western Michigan University

Dr. Edmund Tsang, Western Michigan University 


\title{
An Innovative Redesign of Statics: Approach and Lessons Learned
}

\begin{abstract}
Statics has been traditionally a difficult course as measured by student passing rate (the percentage of students getting a $\mathrm{C}$ or better). At Western Michigan University in Kalamazoo, Michigan, the passing rate of students enrolled in Statics for the previous 5 years has been less than $60 \%$. Since Statics is a required course for students majoring in aerospace engineering, civil engineering, construction engineering, industrial engineering, and mechanical engineering, improving the teaching and learning effectiveness of Statics can have a major impact on retention by virtue of the large number of students affected.

Studies have shown that students benefit when they are actively engaged in the learning process and they are active participants in the classroom, as opposed to passively listening to lectures. This paper describes a course redesign of Statics aimed to improve student learning and success. Traditionally Statics has been taught in either three 50-minute or two 75-minute lecture format. The redesigned course is hybrid, combing traditional classroom lectures and flipped classroom activities. Each week the course has a 50-minute traditional lecture, a 50-minute recitation session, and a 170-minute recitation session. In the recitation sessions, students solve a set of problems assigned by the instructor and the answers they submit are instantly graded. During the process, they received prompt feedback and answers to their questions from the instructor and teaching assistants. In addition, over 60 on-line videos were created so students can watch and learn at home. During spring and fall semesters of 2014, bother traditional and redesigned Statics courses were offered to the students, which allowed a comparison of the two approaches. Data from the past several years were also collected for further comparison. Student survey was conducted and the results were analyzed. Preliminary results on student performance and their perceptions about the course redesign will be presented. A list of lessons learned was identified. The preliminary results are promising and we are planning to implement the redesigned methodology to other engineering fundamental mechanics courses.
\end{abstract}

\section{Introduction}

Statics is a sophomore-level course covering topics including equilibrium of force systems; analysis of trusses, frames and machines; centroid; and moment of inertia of areas. Statics serves as a prerequisite for many subsequent courses including dynamics, mechanics of materials, etc. Statics poses special challenge to engineering students because it is often the first engineering science course they take. Moreover, students who have trouble with Statics often perform poorly in subsequent courses.

Traditionally, Statics has been taught in face-to-face lectures. The traditional lecture format prevents the students from pausing to reflect and understand what is being explained and they may often miss important points. A goal of Statics is to have students learn to solve problems independently, which is a practice-intensive and time-consuming effort for which the lecture can provide guidance yet relatively little direct assistance. The traditional lecture is an instructorcentered, relatively passive method of learning. While lecturing still remains an effective and 
important way of conveying knowledge, it is critical to get students engaged in active learning through activities such as solving problems, working with each other, asking questions and getting feedback.

To enhance student learning in Statics, researchers at various institutions have explored other methods for teaching Statics, such as developing concept map and quantifying students' conceptual understanding ${ }^{[1,2]}$, developing on-line homework or learning modules ${ }^{[3,4]}$, peer-ledteam-learning ${ }^{[5]}$, project-based learning ${ }^{[6]}$, emporium-based course delivery ${ }^{[7]}$. Among them, the flipped classroom method ${ }^{[8,9,10]}$ has gained popularity. In a flipped classroom, the class time is devoted to guided instruction where students work through problems with the instructor present to provide assistance and answer questions. Lectures are delivered through on-line videos which students are required to watch and learn outside the class time.

In this paper, we adopted an innovative hybrid flipped course format ${ }^{[11,12,13]}$. Hybrid flipped courses typically consist of face-to-face classroom interactions, which include traditional lecturing, student solving problems under guidance, labs, group projects, and online web-based instruction, such as online lectures and demonstrations, online quizzes, and on-line discussions. According to a 2010 study conducted by the U.S Department of Education ${ }^{[14]}$, "a hybrid course has the potential to enable instructors to offer students a great range of learning avenues and uphold educational and academic design standards." The purpose of this paper is to present the redesigned hybrid flipped Statics course and the implementation details. The preliminary results of student performance and student surveys will be presented and the lessons learned will be discussed.

\section{Background}

In the College of Engineering and Applied Science at Western Michigan University, Statics is required for students majoring in aerospace engineering, civil engineering, construction engineering, electrical engineering, industrial \& entrepreneurial engineering, and mechanical engineering. It is a 3-credit-hour course that has been taught traditionally either in three 50minute or two 75-minute face-to-face lecture format. The average enrollment for the past 5 years has been between 120 and 150 students per semester.

Statics has been traditionally a difficult course in the college as measured by passing rate (the percentage of students getting a $\mathrm{C}$ or better). The passing rates and the average course GPA (grade point average) in Statics from fall 2010 to fall 2013 are shown in Table 1.

Table 1 Passing rates in Statics over a three-year period

\begin{tabular}{|c|c|c|c|c|}
\hline Semester & Session & Enrollment & Passing rate & Average GPA \\
\hline \multirow{3}{*}{ Fall 2013 } & 1 & 60 & $50 \%$ & 1.64 \\
\cline { 2 - 5 } & 2 & 49 & $55 \%$ & 1.64 \\
\cline { 2 - 5 } & 3 & 32 & $59 \%$ & 1.92 \\
\cline { 2 - 5 } & 4 & 30 & $60 \%$ & 1.55 \\
\hline \multirow{3}{*}{ Spring 2013 } & 1 & 58 & $78 \%$ & 2.29 \\
\cline { 2 - 5 } & 2 & 60 & $50 \%$ & 1.73 \\
\cline { 2 - 5 } & 3 & 51 & $35 \%$ & 1.38 \\
\hline
\end{tabular}




\begin{tabular}{|c|c|c|c|c|}
\hline \multirow{3}{*}{ Fall 2012 } & 1 & 75 & $52 \%$ & 1.71 \\
\cline { 2 - 5 } & 2 & 48 & $60 \%$ & 1.79 \\
\cline { 2 - 5 } & 3 & 38 & $66 \%$ & 1.93 \\
\hline \multirow{3}{*}{ Spring 2012 } & 1 & 73 & $48 \%$ & 1.73 \\
\cline { 2 - 5 } & 2 & 62 & $53 \%$ & 1.81 \\
\cline { 2 - 5 } & 3 & 59 & $36 \%$ & 1.34 \\
\hline \multirow{2}{*}{ Fall 2011 } & 1 & 123 & $50 \%$ & 1.74 \\
\cline { 2 - 5 } & 2 & 55 & $55 \%$ & 1.82 \\
\hline \multirow{2}{*}{ Spring 2011 } & 1 & 73 & $44 \%$ & 1.57 \\
\hline \multirow{2}{*}{ Fall 2010 } & 2 & 52 & $44 \%$ & 1.43 \\
\cline { 2 - 5 } & 1 & 37 & $51 \%$ & 1.78 \\
\hline & 2 & 71 & $28 \%$ & 1.08 \\
\hline
\end{tabular}

As shown in Table 1, the average course GPA is less than 2.00 for 18 out of 19 course offerings. In only 1 out of 19 course offerings, passing rate exceeds $70 \%$; in 15 out of 19 course offerings, the passing rate is less than $60 \%$. The low passing rate of Statics negatively impacts the $2^{\text {nd }}$-to$3^{\text {rd }}$-year retention rate of the college. Therefore, an effort to redesign Statics took place in 2013 with a pilot redesigned course implemented in spring semester of 2014. Beginning spring 2014, students are given the options of enrolling in two redesigned Statics sections taught by two faculty members or a traditional section taught by another faculty.

\section{Course Redesign}

\section{$\underline{\text { Format }}$}

The redesigned course consists of one 50-minute lecture per week; one 50-minute and one 170minute problem-solving recitation session. Typically, during the lecture session, the instructor explains the theory associated with the topics covered in the week and solves some relatively simple examples. Before the recitation sessions, students are asked to read the relevant textbook sections and watch the related on-line videos to prepare for the recitation session. In the recitation sessions, students solve a set of problems which are due at the end of the sessions to gain a deeper understanding of the course materials. In the 170-minute recitation sessions, besides problems solving, students often have quizzes, mid-term exams, or the instructor may spend time demonstrating more difficult examples.

Students work the assigned problems on paper and submit their results online for immediate feedback. During recitation, peer discussion is allowed and encouraged. While the same set of problems is assigned to all students, some of the numerical values in each problem are randomly generated to prevent students from simply copying their classmate's answer. The instructor and student teaching assistants (TAs) are always present to assist the students and answer their questions.

\section{$\underline{\text { Assignments }}$}

In each recitation session, 2 to 4 problems for the 50-minute recitation and 6 to 10 problems for the 170-minute recitation are assigned to students through MasteringEngineering ${ }^{\circledR}$, and the 
assignment is due at the end of the session. There are two advantages using the web-based assignment system. First, the answer submitted by students is instantly graded and if it is incorrect, the system may give a hint on what might have gone wrong. Students are allowed six opportunities to enter an answer before the problem is marked as incorrect and they lose all the points assigned to that problem. Second, in most of the problems at least one numerical value is randomly changed thus students cannot copy other's answer.

Besides the recitations, each week students get homework assignments typically consisting of 8 to 10 problems. Homework is also assigned through MasteringEngineering ${ }^{\circledR}$ and automatically graded by the system.

\section{$\underline{\text { Online Video }}$}

A total of sixty-four video clips were created by the instructors in spring 2014 and fall 2014. The majority of the videos are step-by-step solutions to example problems, with only a few focused on explaining concepts. The problem-solving videos show the instructor's handwriting on a screen accompanied by the instructor thinking out loud in solving the problem. The videos are purposed to mimic solving examples in face-to-face lecture. The videos were created using TechSmith Relay ${ }^{\circledR}$ and then stored in the university's media site. Videos are available online to allow student 24/7 access anywhere they wish to study, and for multiple viewing and pausing. In order to keep the students engaged, the videos are typically around 10 minutes long. Figure 1 shows a screen shot of one problem-solving video.

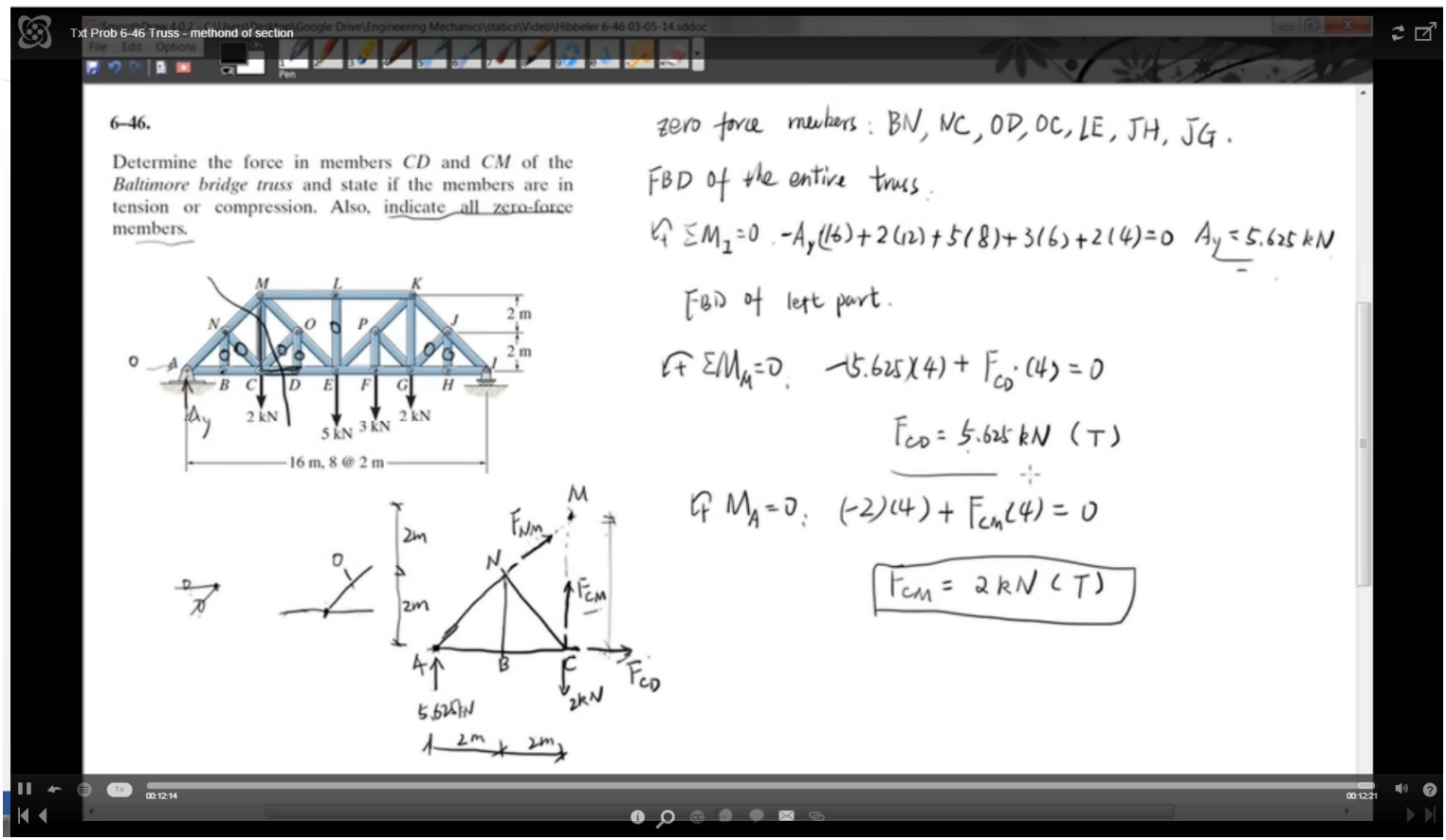

Figure 1 Screen shot of a video example

The University media site is able to track how the online videos are utilized by students. The video usage report showed that all Statics videos were visited a total of 6,300 times and 540 
hours during 2014. The total views per video ranged from 27 to 235 times and the total time watched per video ranged from 1.5 to 26 hours.

\section{Results and discussion}

\section{$\underline{\text { Student Performance Data }}$}

A comparison between students' performance in redesigned and traditional Statics courses is shown in Table 2. The grading system for each group is shown in the footnote to Table 2. All students took the same final exam thus the average final exam scores with the corresponding standard deviations in parentheses are also shown in the table.

Table 2 Summary of student performance in spring and fall 2014

\begin{tabular}{|c|c|c|c|c|c|}
\hline Semesters & Group & Enrollment & $\begin{array}{l}\text { Final Exam } \\
\text { Score }\end{array}$ & $\begin{array}{l}\text { Average } \\
\text { GPA }\end{array}$ & $\begin{array}{l}\text { Passing } \\
\text { rate }\end{array}$ \\
\hline \multirow[t]{2}{*}{ Spring 2014} & Traditional $^{\mathrm{a}}$ & 23 & $68.1(18.8)$ & 1.78 & $52.2 \%$ \\
\hline & Redesigned $^{b}$ & 88 & $70.8(17.9)$ & 2.00 & $61.4 \%$ \\
\hline \multirow[t]{2}{*}{ Fall 2014} & Traditional $^{\mathrm{a}}$ & 30 & $65.8(22.0)$ & 2.07 & $66.7 \%$ \\
\hline & Redesigned $^{b}$ & 95 & $65.9(16.2)$ & 2.10 & $70.5 \%$ \\
\hline
\end{tabular}

${ }^{a}$ Grading system: $5 \%$ attendance, $15 \%$ quizzes, $10 \%$ homework, $51 \%$ midterms, $19 \%$ final

${ }^{\mathrm{b}}$ Grading system: $15 \%$ quizzes, $15 \%$ recitation, $5 \%$ homework, $48 \%$ midterms, $17 \%$ final

From the table we can see that students in the redesigned class outperformed students in the traditional class in both semesters, though T-tests of the two student groups assuming unequal variances showed an insignificant difference between the final exam scores at the $95 \%$ confidence level. Generally, the standard deviation of final exam score in the redesigned class appears to be smaller than the traditional class. In addition, it was the instructors' perception that overall, students in the redesigned class had a better understanding of fundamental concepts and were more skilled in solving problems than students in the traditional class. The limitation is that the data collected in this analysis corresponds to only two semesters which may not be fully conclusive; we will continue to collect student performance data and compare the results. It is worth noting that the grading system used for the traditional and redesigned classes were slightly different: the total percentages of exams are $70 \%$ for traditional course and $65 \%$ for redesigned course. To better compare student performance, we intend to adjust the grading for the redesigned course in spring 2015 to $12 \%$ quizzes, $12 \%$ recitation, $5 \%$ homework, $52 \%$ midterms and $19 \%$ final.

\section{$\underline{\text { Student Survey }}$}

Anonymous student surveys were conducted near the end of spring 2014 and fall 2014 semesters. The survey contains eighteen statements related to student's perception of the redesigned course, and students answer each question with a scale of 1 (strongly disagree) to 5 (strongly agree). At the end there is a comment section. Table 3 presents the list of statements. Sixty-seven (67) and seventy-nine (79) surveys were collected in spring 2014 and fall 2014, respectively. Table 4 and Table 5 show the student responses to each statement in spring 2014 
and fall 2014. Figure 2 and Figure 3 show the mean score and standard deviation of each statement in spring 2014 and fall 2014.

Table 3 List of Student Survey Statements

1. The lecture adequately prepared me to do the recitation assignments

2. I always read the related textbook sections before the recitation sessions

3. I always watch the related online videos before the recitation sessions

4. The online videos helped me learn the material

5. Having the videos to refer to and to be able to pause and review helped me learn the materials

6 . Working the recitation assignments helped me learn the material

7. I worked more problems in this course than I did in a traditional lecture course

8. The amount of work assigned in the recitation sessions is too much

9. It was beneficial to work the recitation problems where help was available

10. The student assistants were knowledgeable and helpful

11. The 170 minute time period of a recitation session is too long

12. The computer lab provided an adequate environment to work on recitation assignments

13. Working the homework assignments helped me learn the material

14. Homework assignments are unnecessary since we already have solved many problems in recitation sessions

15. I liked the more frequent midterm exams with each covering less material

16. I believe that I learned the material better using the new approach than the traditional approach

17. Overall, I like the new approach better than the traditional approach

18. I prefer to use the new approach to teach subsequent engineering mechanics courses than the traditional lecture approach

Table 4 Student survey responses in spring 2014 (Total 67)

\begin{tabular}{|c|l|l|l|l|l|}
\hline Statements & $\begin{array}{l}\text { Strongly } \\
\text { agree }\end{array}$ & Agree & Neutral & Disagree & $\begin{array}{l}\text { Strongly } \\
\text { Disagree }\end{array}$ \\
\hline $\mathbf{1}$ & 12 & 25 & 23 & 5 & 2 \\
\hline $\mathbf{2}$ & 3 & 10 & 20 & 23 & 11 \\
\hline $\mathbf{3}$ & 7 & 18 & 29 & 12 & 1 \\
\hline $\mathbf{4}$ & 23 & 28 & 14 & 0 & 2 \\
\hline $\mathbf{5}$ & 30 & 23 & 11 & 1 & 2 \\
\hline $\mathbf{6}$ & 39 & 21 & 5 & 2 & 0 \\
\hline $\mathbf{7}$ & 48 & 12 & 5 & 1 & 1 \\
\hline $\mathbf{8}$ & 10 & 22 & 25 & 8 & 2 \\
\hline $\mathbf{9}$ & 42 & 20 & 4 & 0 & 1 \\
\hline $\mathbf{1 0}$ & 37 & 23 & 7 & 0 & 0 \\
\hline $\mathbf{1 1}$ & 6 & 11 & 19 & 21 & 10 \\
\hline
\end{tabular}




\begin{tabular}{|l|l|l|l|l|l|}
\hline $\mathbf{1 2}$ & 28 & 33 & 4 & 1 & 1 \\
\hline $\mathbf{1 3}$ & 24 & 37 & 5 & 0 & 1 \\
\hline $\mathbf{1 4}$ & 2 & 7 & 13 & 33 & 11 \\
\hline $\mathbf{1 5}$ & 28 & 29 & 7 & 3 & 0 \\
\hline $\mathbf{1 6}$ & 29 & 26 & 10 & 1 & 1 \\
\hline $\mathbf{1 7}$ & 32 & 24 & 6 & 3 & 2 \\
\hline $\mathbf{1 8}$ & 34 & 19 & 10 & 4 & 0 \\
\hline
\end{tabular}

Table 5 Student survey responses in fall 2014 (Total 79)

\begin{tabular}{|c|l|l|l|l|l|}
\hline Statements & $\begin{array}{l}\text { Strongly } \\
\text { agree }\end{array}$ & Agree & Neutral & Disagree & $\begin{array}{l}\text { Strongly } \\
\text { Disagree }\end{array}$ \\
\hline $\mathbf{1}$ & 13 & 26 & 15 & 16 & 8 \\
\hline $\mathbf{2}$ & 3 & 8 & 22 & 21 & 25 \\
\hline $\mathbf{3}$ & 6 & 12 & 31 & 19 & 11 \\
\hline $\mathbf{4}$ & 31 & 23 & 15 & 7 & 3 \\
\hline $\mathbf{5}$ & 36 & 27 & 10 & 4 & 2 \\
\hline $\mathbf{6}$ & 42 & 22 & 12 & 1 & 2 \\
\hline $\mathbf{7}$ & 55 & 15 & 5 & 4 & 0 \\
\hline $\mathbf{8}$ & 15 & 25 & 23 & 12 & 4 \\
\hline $\mathbf{9}$ & 43 & 25 & 8 & 2 & 1 \\
\hline $\mathbf{1 0}$ & 34 & 29 & 11 & 5 & 0 \\
\hline $\mathbf{1 1}$ & 15 & 17 & 25 & 13 & 9 \\
\hline $\mathbf{1 2}$ & 37 & 29 & 9 & 4 & 0 \\
\hline $\mathbf{1 3}$ & 27 & 34 & 11 & 6 & 1 \\
\hline $\mathbf{1 4}$ & 5 & 16 & 18 & 27 & 13 \\
\hline $\mathbf{1 5}$ & 38 & 27 & 9 & 2 & 3 \\
\hline $\mathbf{1 6}$ & 39 & 19 & 12 & 5 & 3 \\
\hline $\mathbf{1 7}$ & 39 & 18 & 9 & 8 & 4 \\
\hline $\mathbf{1 8}$ & 40 & 20 & 7 & 6 & 5 \\
\hline
\end{tabular}

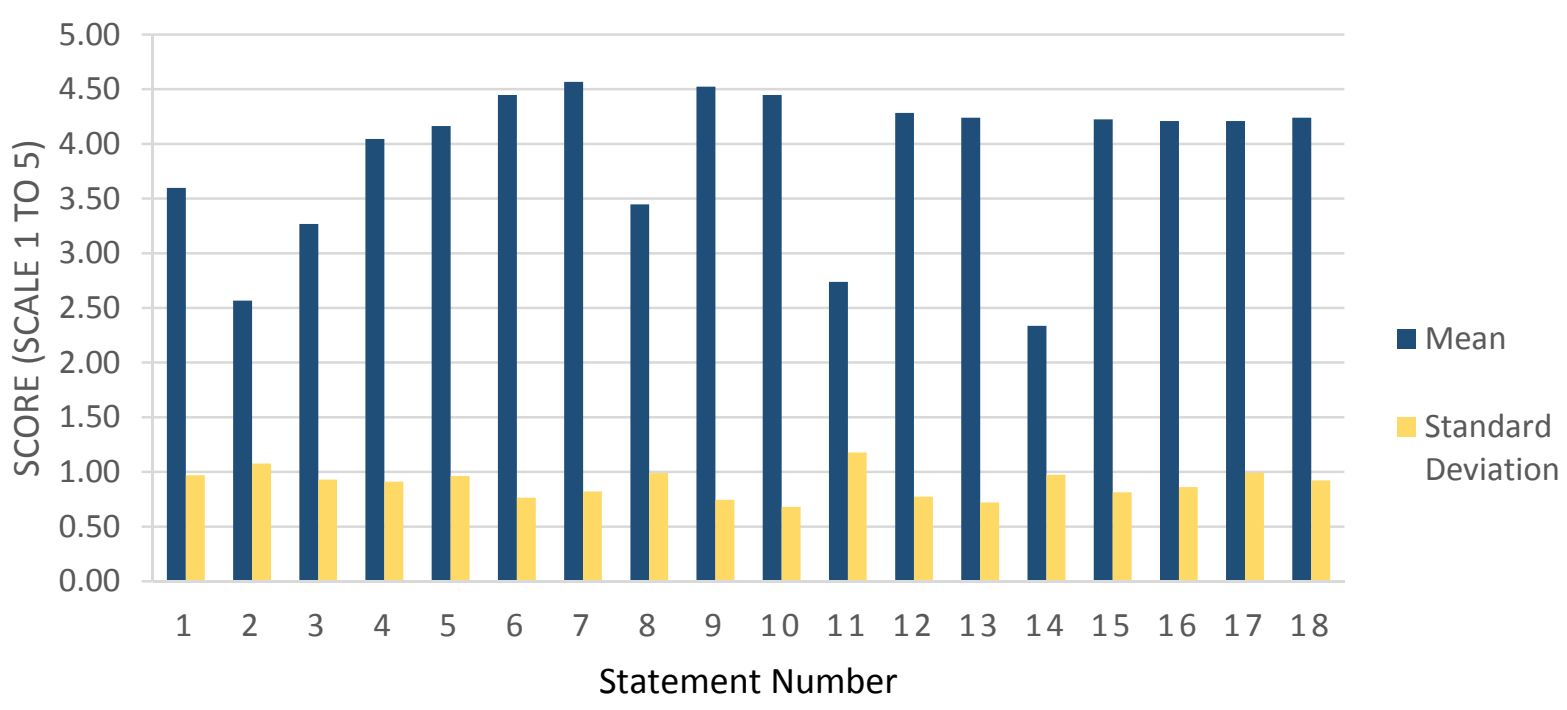


Figure 2 Student survey score in spring 2014

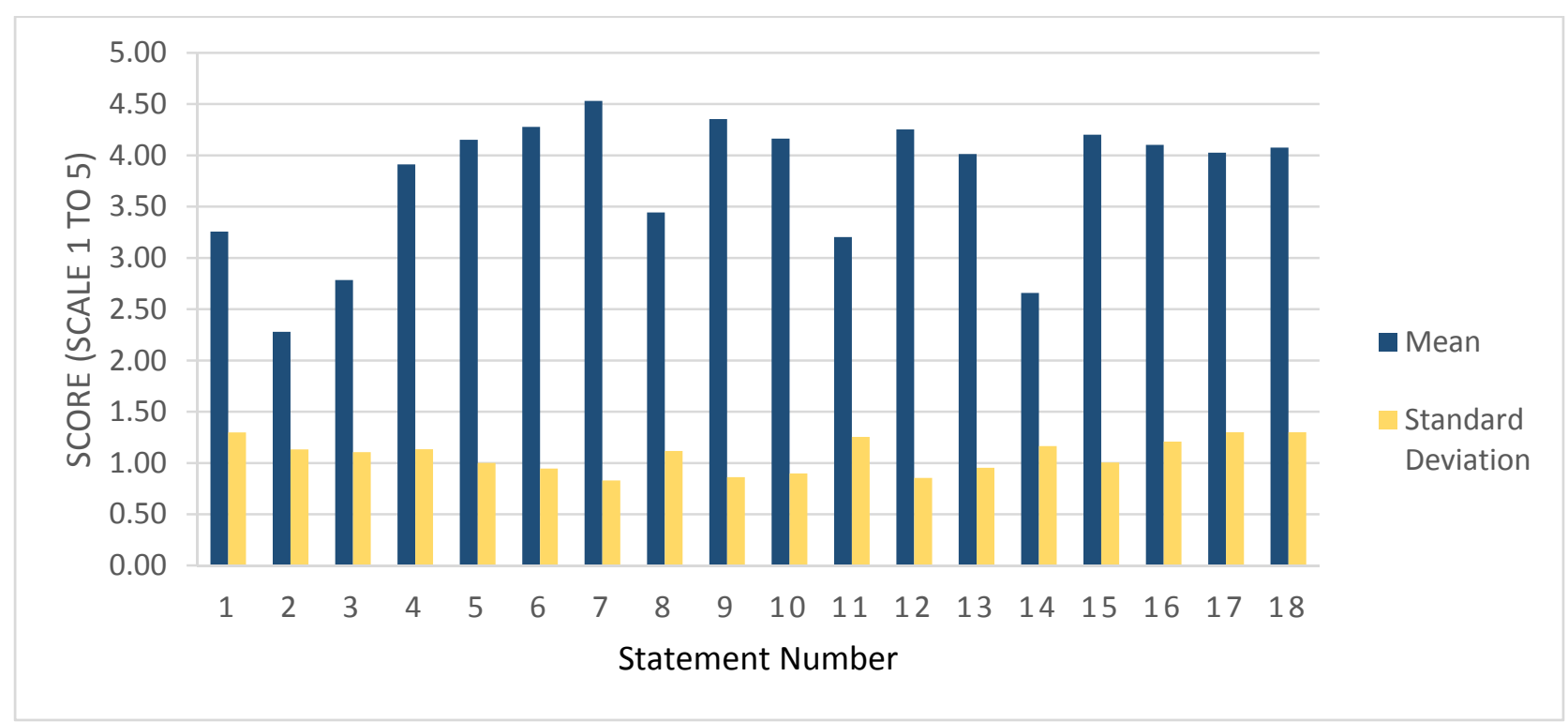

Figure 3 Student survey score in fall 2014

The survey results showed that most students liked the redesigned teaching approach. Students expressed that they were able to work more problems and learn the materials better in the redesigned format. Overall the feedback for the redesigned course was quite positive.

An important observation drawn from the survey results is that the students' preparation for recitation sessions is inadequate. Since there is only one 50-minute lecture per week, the instructors expected the students to read the related sections in the textbook and watch the video examples before the recitations, so they are adequately prepared to solve problems during the recitation session. However, from the student responses in statements 2 and 3 about prerecitation activities, a significant number of students did not do what was expected and were not properly prepared for the recitation sessions.

In the comment section, more students showed preference for the redesigned course, although there were a few negative comments. Table 6 provides samples of comments regarding students' overall impression about the redesigned course. This is not an exhaustive list but a sample of positive and negative comments.

Table 6 Sample of student comments

"The strengths of this course is that it we had a new way of being taught Statics by doing more problems, and I thought that helped a ton."

"I liked how this course was changed from strictly lecture to lecture with recitation because it gave me the opportunity to get more familiar with the material and guidance when I got stuck on a problem." 
"I loved the way that the course was set up, it made it so that you had to know how to do it. I liked that we had a lot of time in class to just work on problems by ourselves, as opposed to being lectured and watching."

"This is my second time taking this class and having the recitation sessions have helped a lot. Before you would see something in lecture once and then that was it. If you couldn't clearly understand it you would get bad grades on all of the homework. Having this time available to ask questions has helped with understanding tremendously."

"The recitation sessions that we spent 3 hours like a lab every week working on the problems helped me a great deal, definitely a better way for me to learn than standard classes every day of the week."

"The support from the Teachers Assistant in the recitation period was very good and helped me learn a lot of the new material."

"More lecture time instead of the lab. The lab was not helpful."

"The new approach was not executed properly."

"SLOW DOWN! The professor lectures too fast. We need to take more time to lecture over the material and he needs to not rush everything all of the time. When you sit in class and haven't seen the material before it's a lot to take in at once.

The most common complaint was that there were too many problems assigned for each recitation session and that the allotted time was not sufficient to complete the assignments. This is probably associated with the inadequate preparation for the recitation. Another comment that was mentioned by multiple students was the need for more lecture time to obtain proper preparation for recitation. Both comments indicated that students need time to adjust to the new teaching approach and to complete the pre-assignments before recitation.

\section{Lessons learned}

Based upon the redesign experience and the collected evidence, we have identified a list of lessons learned.

\section{$\underline{\text { Careful Planning and Teamwork }}$}

The initiative to reform Statics started in early 2013 and a Statics redesign team was formed in spring 2013. The redesign team included the associate dean for undergraduate programs and assessment and two faculties who are teaching Statics. A literature review was conducted to identify some best practices in teaching Statics. Regular meetings were held to review and discuss the current Statics teaching approach, analyze student performance, discuss the redesign strategy, layout the redesigned format, and explore the technical resources available to deliver the online videos. In summer 2013, the team systematically analyzed the historical student performance data. Before the formal implementation of the redesigned course, the structure of the redesigned course was laid out and the recitation problems were assigned through MasteringEngineering ${ }^{\circledR}$. A student assistant was hired to go through the assigned problems, to 
ensure the soundness of the workload in each recitation, and to give feedback about the recitations. During the implementation semester in spring 2014, the team frequently met or discussed through emails in order to continuously improve the redesigned course. All of these careful planning and teamwork are key aspects of the success of the redesign.

\section{Learning through Problem-solving}

One of the major elements in the redesigned course is a student-centered pedagogy in which students learn about a subject through problem-solving ${ }^{[15,16]}$. In recitations, the role of the instructor has shifted from teaching to facilitate learning by supporting, guiding and monitoring the learning process. While assisting the students during recitations, it is important that the instructors and the TAs do not just tell the students what to do, but rather help them recall the knowledge they have acquired and guide them to take on the problems by themselves. The tutors must build the students' confidence and encourage them while also stretching their understanding. Also, the students are encouraged to discuss the problem with other students in the beginning, but after the initial team work, students must work independently.

\section{$\underline{\text { Peer Assisting Learning }}$}

During the recitation sessions of the redesigned course, the students solve problems by working in small teams, under the guidance of undergraduate TAs who have successfully completed the course recently and have been trained as peer leaders. This instructional model is grounded in constructivism with the principle that "student understanding is actively constructed through individual and social process" [17]. The setting provides more focus on individual student needs rather than instructor-directed activities, which may address the needs of a few students but do not meet the needs of all students. Also, it accommodates the needs of students who feel more comfortable interacting with their peers.

The student TAs play an important role in the recitations. The undergraduate students recruited in spring 2014 were from the previous Statics classes taught by the two instructors in the redesign team. In fall 2014, we recruited several new TAs who have just completed Statics in spring 2014 under the new teaching approach. The instructors and the TAs constantly communicated throughout the semester to identify the problems and improve execution of the recitations. Overall the peer leaders performed well and received students' praises in the course evaluation and student surveys.

\section{$\underline{\text { Built-in Formative Assessment }}$}

When students solve problems in recitation sessions, they submit the answer online and get instant feedback. The MasteringEngineering ${ }^{\circledR}$ system evaluates their answer and indicates whether it is correct or incorrect. If their answer is close, the system provides hints that guide students to determine whether the error might be due to a rounding error, or incorrect units or signs. The students have six chances to enter the correct answer. Generally, if the students could not get the correct answer in the first a few tries, most of them turn to their classmates, or the instructors or TAs for help. Instructors and TAs quickly check their work and point out what went wrong. This built-in formative assessment is able to provide instant feedback not only to 
the students, but also to the instructors. The instructors can view individual student's answer as well as the statistical report of all the answers of all problems, which enable them to identify the challenging topics and reinforce them through subsequent reviews, homework assignments, etc. We feel the formative assessment facilitates the development of student self-assessment and provides quality feedback to students, and in the meantime provides the instructors valuable information to help them shape their teaching.

\section{Enforcement of the Pre-recitation Study}

One of the difficulties encountered in flipped classroom teaching is how to ensure student proper pre-class preparation. We also sense that in our redesign, this is a challenge that still needs significant improvement. Obviously, one 50-minute lecture is not sufficient to get students ready for recitations so they are required to read the related textbook sections and watch the online videos prior to recitation. However, instructors have little control over whether the students have read the textbook as required. As a matter of fact, student survey responses indicated that a small number of them read the textbook before the recitation. In terms of video watching, although the total views and viewing time of a video can be obtained, it is hard to track individual viewing data. One way to assess or enforce student pre-recitation preparation is to give a short quiz at the beginning of recitation. While this would take precious time from the already busy schedule, it is something we may need to implement in the future.

\section{Conclusion}

This paper described a complete redesign of Statics using the hybrid flipped classroom model. With two semesters' experience of the implementation, we have identified areas of success as well as those that need continuous improvement. Overall, the redesigned course is promising for improving student performance as demonstrated by average course GPA and passing rate. The student performance data collected in the two semesters showed some evidence that the students performed better in the redesigned approach. A longer study period is needed to make firm conclusion and we will continue collecting and analyzing the data.

With any significant change in the pedagogical approach, there are always some initial resistances and challenges that the instructors and students need to overcome. Instructors need to devote a significant amount of time and effort at the beginning. However, once the redesigned course is implemented, the work load of the instructors actually will be reduced. The students also need to make adjustments to the new teaching style, but once getting used to it, they will benefit from the active learning promoted by the redesigned approach. In the first two semesters of the implementation of the redesigned course, the student and instructor feedback was overall positive.

The successful redesign experience also can be extended to other engineering fundamental mechanics courses. In fact the same model was applied in another fundamental engineering mechanics course starting in fall 2014, and the college is planning to implement the model in a third mechanics course in the near future. 


\section{References}

[1] Steif PS, Dollar A, Dantzler JA. "Results from a Statics Concept Inventory and their Relationship to other Measures of Performance in Statics." Proceedings of the ASEE Frontiers in Education Conference, Indianapolis, IN, October, 2005

[2] Pierre-Antoine R, Sheppard SD. "Utilizing Concept Maps to Improve Engineering Course Curriculum in Teaching Mechanics.” Proceedings of the ASEE Annual Conference and Exposition, Indianapolis, IN, June, 2014

[3] Caldwell BW, Halupa CM. "A Pilot Study of an Online Accelerated Statics Course with Intensive Video Delivery." Proceedings of the ASEE Annual Conference and Exposition, Indianapolis, IN, June, 2014

[4] Dollar A, Steif PS. “An Interactive, Cognitively Informed, Web-based Statics Course.” International Journal of Engineering Education, Vol. 24, No. 6, pp. 1229-1241, 2008.

[5] Villatoro ML, Moreira M, Liang Y. "Successful implementation of PLTL for CMCE 1110." Conference Proceedings of the Peer-Led Team Learning International Society, New York City, May, 2012.

[6] Atadero RA, Balgopal MM, Rambo-Hernandez KE, Casper AMA. "Project-Based Learning in Statics: Curriculum, Student Outcomes, and On-going Questions.” Proceedings of the ASEE Annual Conference and Exposition, Indianapolis, IN, June, 2014

[7] Rais-Rohani M, Walters A, Vizzini A. "Emporium Based Redesigned of Statics: An Innovative Approach to Enhance Learning and Reducing Costs." Proceedings of the ASEE Annual Conference \& Exposition, Louisville, KY, June, 2010.

[8] Papadopoulos C, Santiago-Román A. "Implementing an Inverted Classroom Model in Engineering Statics: Initial Results.” Proceedings of the ASEE Annual Conference \& Exposition, Louisville, KY, June, 2010.

[9] Swartz B, Velegol SB, Laman JA. "Three approaches to Flipping CE Courses: Faculty Perspectives and Suggestions." Proceedings of the ASEE Annual Conference and Exposition, Atlanta, GA, June, 2013

[10] Steif PS, Dollar A. "Web-Based Statics Course Used in an Inverted Classroom.” Proceedings of the ASEE Annual Conference \& Exposition, Austin, Texas, 2009.

[11] Young JR. "Hybrid Teaching Seeks to End the Divide between Traditional and Online Instruction." The Chronicle of Higher Education, Mar. 22, 2002. Web. Jan 26, 2015, http://chronicle.com/article/Hybrid-TeachingSeeks-to/18487

[12] Everett JW, Morgan, JK, Stanzione III JF. “A Hybrid Flipped First Year Engineering Course.” Proceedings of the ASEE Annual Conference and Exposition, Indianapolis, IN, June, 2014

[13] Riffell S, Sibley D. "Using web-based instruction to improve large undergraduate biology courses: An evaluation of a hybrid course format." Computers \& Education, Vol. 44, No. 3, 217-235, 2005

[14] Means B, Toyama Y, Murphy R, Bakia M, Jones K. "Evaluation of Evidence-Based Practices in Online Learning: A Meta-Analysis and Review of Online Learning Studies." U.S. Department of Education, Office of Planning, Evaluation, and Policy Development, Policy and Program Studies Service, Washington D.C., 2010 [15] Allen DE, Duch BJ, Groh SE. "The Power of Problem-based Learning in Teaching Introductory Science Courses.” In L. Wilkerson \& W. H. Gijselaers (Eds.), Bringing problem-based learning to higher education: Theory and practice (pp. 43- 52). San Francisco: Jossey-Bass, 1996

[16] Wood DF. "Problem Based Learning." British Medical Journal, Vol. 326, No. 7384, pp. 328-330, 2003.

[17] Committee on Undergraduate Science Education, National Research Council. "Transforming undergraduate education in Science, Mathematics, engineering, and technology." National Academy Press, Washington, DC, 1999. 